\title{
Social Network, Interpersonal Communication System and Loneliness- the Living Situation of Networked Individuals in Mainland China
}

\author{
Zhengke Fu, Mengsi Yan \\ Department of art and communication, Ningbo Institute of technology, Zhejiang University, Zhejiang, \\ 315000, China \\ Department of Humanity, Ningbo Financial University, Zhejiang, 315000, China
}

Keywords: social network; communication system; loneliness

\begin{abstract}
This research tries to probe how social network affect loneliness and how the personal communication network affect loneliness. The study uses the survey as the major research method, also the deep discussion is also used to get the detail of the story of the subjects. The study gets 1033 questionnaire, after deleting the repeated and bad questionnaire, finally gets 995 valid questionnaire, and gives a vivid description of the networked individualism in China. The details of findings is presented in the conclusion part.
\end{abstract}

\section{Introduction}

How might the social network and communication system work hand in hand to affacour daily life is a more and more important question. Wilman in his book "Networking Individualism: The New Socialized Operating System", Networked Individualism This core concept consists of two dimensions. The first is actually the personal-social network, and the second is the personal communication network system. Some studies have explored how networked individualism may change the process of social participation, but the impact on social life is less explored. Therefore, this study will analyze how social networks and self-distribution systems affect individual social psychology.

\section{Problems Discussed}

The discussed model is given as follow:

$$
\text { UCLAloneliness }=a+b_{1} X_{1}+b_{2} X_{2}+b_{3}(\text { female })+b_{4}(\text { education })+b_{5}(\text { age })
$$

Some basic concepts associated with the problem are presented as follows

Social networks:

This is X1, which is the independent variable of interest. Social network represents the situation of social network we had.

Communication network:

This is $\mathrm{x} 2$, which is the independent variable of interest. The Communication network represents the communication situation of people.

UCLA loneliness:

This is $\mathrm{Y}$, which is the dependent variable of interest. The UCLA represents the loneliness situation of people.

Background variables:

They are key demographic variables we added to control. The demographic variables includes sex, age and education.

\section{Definition 1}

For social network

If people answer the social network questionnaire, then we get his different aspect of social network condition 


\section{Definition 2}

For communication system

if people answer the communication system questionnaire, then we get his different aspect of communication system condition.

\section{Definition 3}

For loneliness, if people answer the UCLA questionnaire, then we get his extent of loneliness.

Two assumptions are given as follows:

i) Different ICT might significantly affect UCLA

ii) The social network might significantly affect UCLA

\section{Social Capital}

The concept of social capital has different conceptualization methods, and the common point is that they all emphasize that social relations can bring benefits to individuals. In the study of sociology, there are different conceptualizations of social capital. Bourdieu uses the concept of social capital to explain how inequities in society are generated [1]. In this study of social paths, social relations are used to explain how people in different social status obtain benefits from the places they know [2]. The main focus of Bourdieu is the vertical social relationship between different social classes. Putnam is more about defining the benefits of social relations to individuals within the hierarchy from within the various social classes. Social capital can be at the community level or at the individual level [3]. Social capital at the social level is defined as formal social capital (organizational membership and organizational participation) and informal social capital (interaction with neighbors in society, etc.). In his book "Beaching Alone", Putnam pointed out that informal social capital is gradually declining with the development of society [4]. Willman and others continue Putnam's definition of social capital, divided into participatory social capital and networked social capital[5], and further attitudes (such as interpersonal trust, and The dimension of social belonging) is placed under the concept of social capital [6]. Although the definition of social capital is diverse, these definitions often have two things in common: 1. Pay attention to the social relationship between people, 2. Pay attention to the tangible benefits that social relations can bring (such as social support, Companionship, the flow to the upper echelons of society).[1-6]

Social capital can be divided into two types, one is bridging social capital, and the other is bounding social capital. Bridging social capital is most commonly found in various types of volunteer organizations, because the premise of establishing these organizations is trust and cooperation [7]. The production of social capital is de-stratified. Because of this type of communication, bridging social capital enables individuals to derive benefits derived from different types of social relationships. So in these organizations, people from different backgrounds can exchange their experiences and their views on the world. Similarly, those who succeed in job hunting are often those who have strong social capital. Bridging social capital stems from weak relationships, providing us with information resources and alternative worldviews[8], so bridging social capital can be produced from those weak relationships when needed. Although bridging social capital often contains a large number of social relationships, it does not provide deep emotional support [9]. While bounding social capital and utilitarian-oriented bridging social capital, it can provide deeper social support and emotional support for individuals.[7-9]

The benefits of social capital play an important role in individual psychology and well-being. The social relationship has many implications because social relationships are associated with a sense of belonging (Baumeister \& Leary, 1995. Studies have pointed out that good social relations play an important role in people's mental and physical health, so people have the motivation to connect with others[10]. When ideal social relationships are not available, people may face higher risks or risk of losing control. In Durkheim's book "On Suicide," Durkheim once pointed out that one of the important reasons for modern suicide is the lack of ideal social relations.[10-12]

The definition of social capital in this study is from the level and the individual. The social capital is regarded as a social resource that can bring benefits to the individual. It refers to the individual obtaining resources and help from his own social network. For modern people, they 
establish their own social relations with self as the center. Wellman calls it "networked individualism", and individuals get the resources they need through interaction with different types of social relationships in social networks. .

\section{Social Network as a Resource}

Social network analysis generally has two forms: overall network analysis and self-network analysis. The overall network analysis generally sets a closed group boundary; in contrast, the network emphasizes the social relationship owned by individuals as individuals, and the network is often used to measure the personal network of modern people.

The social network of this study refers specifically to the personal network, which refers to the sum of the social relationships owned by individuals (ie, the relationships they know and communicate) [13]. People are social animals. We obtain various resources from social relationships. Social networks provide individuals with various types of potential or explicit interests.[13, 14]

The resources provided by social networks have an impact on the individual's social psychology. Many studies have pointed out that social networks can provide social resources for modern people[14]. These social resources are important because individuals will evaluate the social relationships in the social networks they own, and thus affect the individual's social psychology, such as the social support or loneliness perceived by the individual. The reason why the state of social networks affects the individual's social psychology is that everyone will evaluate the state of their social relationships.[14]

\section{Personal Communication Network System}

From the perspective of networked individualism, communication extends the social relationship of modern people. In his book "Networking Individualism: The New Socialized Operating System," Wellman includes two core concepts. The first is networked individualism, which is actually a personal-social network, meaning that modern people are different from communication. Closed community, the social relationship structure that exists as the center, the social network of the individual, just like the socialized operating system, the picture imagined in the mind is that modern people are like using the APP in "Apple". Get the resources you want by connecting with different individuals. So how is this social relationship maintained? For modern people, they rely on a network of self-distribution concluded by different media. Just as Parker pointed out that relations occur in communication. Based on communication practices, relationships are established, removed, and re-established[15].

Result

In summary, based on existing theories and research, the following assumptions are made:

H1: The strength of social networks, the number of social relationships, and the characteristics of social networks have a significant impact on UCLA loneliness.

H2: Personal communication network networks have a significant impact on loneliness at different levels.

\section{Data Collection and Analysis}

In order to illustrate the feasibility and effectiveness of the theory, we construct two studies according to examples in literature [16-19]. We solve them by two different approaches. The first is the approach proposed in this paper, and the second approach is the same as the first one except using the regression function to answer the question how might mediated social network impact loneliness.

The measurement of variables are shown as follows:

The first part of the questionnaire asked participants to answer background information

The second part of the questionnaire used to obtain data of social networks[13] and 
communication system[15].

UCLA loneliness. By correcting UCLA loneliness questionnaire by Likert scale measuring loneliness condition of the individual, four topics ranging from 1 (strongly disagree) to 5 (strongly agree) score, the higher the score the higher the feeling of loneliness. To test the stability and the intrinsic validity of the questionnaire, the factor analysis and reliability analysis had been used. The KMO value (.826), is greater than 0.8 , and therefore the questionnaire was suitable for factor analysis. Via factor analysis, factor loading amount of each question item 0.6 , so each question item has good convergent validity. Eigenvalues 1.0 to arrive at a factor of the total variance explained by the amount of (73.123) \%. Internal consistency coefficient (Cronbachs' $\alpha$ ) is (.877), greater than 0.7.The correlation between scale item is is greater than 0.3 , project-related amended greater than 0.5 .

The impact of social network and communicaiton system on UCLA loneliness are shown below:

Table1 multiple regression of social network and communication system on UCLA

\begin{tabular}{lccccccccc}
\hline rcept & EDU & GENDER & AGE & b1 & TOR & VIF & $\begin{array}{c}\text { Adjusted } \\
\text { R sauare }\end{array}$ & F & Durbin-Watson \\
\hline 386 & -.083 & -.004 & -.008 & $-.070^{* * * *}$ & .956 & 1.046 & .047 & 13.286 & 1.946 \\
476 & -.065 & .004 & -.017 & -.041 & .979 & 1.022 & .023 & 6.830 & 1.919 \\
547 & -.055 & .024 & -.024 & $-.084^{* * * *}$ & .997 & 1.003 & .018 & 5.489 & 1.928 \\
343 & -.063 & .021 & -.024 & -.021 & .984 & 1.016 & .003 & 1.861 & 1.916 \\
266 & -.060 & .026 & -.029 & .010 & .963 & 1.038 & .001 & 1.336 & 1.915 \\
441 & -.065 & .019 & -.025 & $-.041^{*}$ & .989 & 1.011 & .005 & 2.275 & 1.909 \\
301 & -.060 & .024 & -.027 & -.003 & .965 & 1.036 & .001 & 1.282 & 1.913 \\
207 & -.075 & .034 & -.021 & $-.057^{* * *}$ & .951 & 1.051 & .008 & 3.076 & 1.903 \\
564 & -.066 & -.005 & -.022 & $-.077^{* * * *}$ & .991 & 1.009 & .056 & 15.763 & 1.925 \\
558 & -.068 & -.001 & -.024 & $-.055^{* * * *}$ & .987 & 1.013 & .030 & 8.559 & 1.911 \\
398 & -.063 & .010 & -.025 & $-.027^{* * *}$ & .986 & 1.015 & .010 & 3.621 & 1.899 \\
542 & -.061 & .006 & -.022 & $-.057^{* * * *}$ & .993 & 1.007 & .032 & 9.167 & 1.909 \\
& & & & & & & & & \\
410 & -.062 & .017 & -.028 & $-.026^{* * *}$ & .994 & 1.006 & .011 & 3.621 & 1.905 \\
\hline $5.01 \mathrm{P}<.001$ & & & & & & & & \\
\hline
\end{tabular}

The results show that the $\mathrm{D}-\mathrm{W}$ in the seven models are 1.946, 1.919, 1.928, 1.916, 1.915, 1.909, $1.913,1.903$, and the $\mathrm{D}-\mathrm{W}$ values are around 2 , indicating that the data is consistent with the sample. The predictive variable $\mathrm{VIF}<5$ for each model indicates that there is no collinearity between the predictor and the control variable in each model.

The table summarizes the results of the regression model. After controlling the demographic variables:

Variable relationship $(\beta=-.070, p<.01)$, familiarity $(\beta=-.084, p<.01)$, ethnic proximity $(\beta=057$, $\mathrm{p}<.01)$ for UCLA loneliness Significant. This means that there is a significant negative impact between having a homogeneous social network and UCLA loneliness.

Therefore, H1a: the size and characteristics of social relationships in individual social networks have a significant impact on UCLA loneliness.

At the same time, the variable aspect network $(\beta=-.077, p<.00)$, mobile network $(\beta=-.055$, $\mathrm{p}<.00)$, the Internet $(\beta=-.027, \mathrm{p}<.01)$, the use of instant messaging networks $(\beta=-.057, \mathrm{p}<.00)$ and social media networks $(\beta=-.026, \mathrm{p}<.01)$ has a significant impact on UCLA loneliness.

Therefore, the use of the H2.1 self-propagating network has a significant impact on UCLA.

\section{Conclusion}

This study has two major Findings: 1st, The impact of the social network to loneliness: The more homogeneous of the social network the lower UCLA. The more the strong and week ties the lower UCLA. 2nd, The impact of personal communication network to loneliness: The personal communication network differently impacts loneliness.

\section{Acknowledgements}

The research work was supported by 
China Department of Education No. 2133

Zhejiang Federation of Humanities and Social Sciences Circles under Grant No. 2015N033,

Zhejiang Provincial Department of Culture under Grant No. 2011-z-756,

Zhejiang Federation of Humanities and Social Sciences Circles under Grant No. 2018N90,

Ningbo Federation of Humanities and Social Sciences Circles under Grant No.17CB-A02

\section{References}

[1] Bourdieu, P., The forms of capital.(1986). Cultural theory: An anthology, 2011: p. 81-93.

[2] Swain, N., Social capital and its uses. Archives Européennes de Sociologie/European Journal of Sociology/Europäisches Archiv für Soziologie, 2003: p. 185-212.

[3] Putnam, R.D., Tuning in, tuning out: The strange disappearance of social capital in America. PS: Political science \& politics, 1995. 28(04): p. 664-683.

[4] Putnam, R.D., Bowling alone: The collapse and revival of American community. 2001: Simon and Schuster.

[5] Wellman, B., et al., Does the Internet increase, decrease, or supplement social capital? Social networks, participation, and community commitment. American behavioral scientist, 2001. 45(3): p. 436-455.

[6] Shah, D.V., J.M. McLeod, and S.-H. Yoon, Communication, context, and community an exploration of print, broadcast, and internet influences. Communication research, 2001. 28(4): p. 464-506.

[7] Stolle, D., Bowling together, bowling alone: The development of generalized trust in voluntary associations. Political psychology, 1998: p. 497-525.

[8] Granovetter, M., The strength of weak ties: A network theory revisited. 1981: JSTOR.

[9] Williams, D., On and off the'Net: Scales for social capital in an online era. Journal of Computer-Mediated Communication, 2006. 11(2): p. 593-628.

[10] Heinrich, L.M. and E. Gullone, The clinical significance of loneliness: A literature review. Clinical psychology review, 2006. 26(6): p. 695-718.

[11] Rahn, W.M. and J.E. Transue, Social trust and value change: The decline of social capital in American youth, 1976-1995. Political Psychology, 1998. 19(3): p. 545-565.

[12] Baumeister, R.F. and M.R. Leary, The need to belong: desire for interpersonal attachments as a fundamental human motivation. Psychological bulletin, 1995. 117(3): p. 497.

[13] Wellman, B., The network is personal: Introduction to a special issue of Social Networks. Social networks, 2007. 29(3): p. 349-356.

[14] Lin, N., Building a network theory of social capital. Connections, 1999. 22(1): p. 28-51.

[15] Parks, M.R., Personal relationships and personal networks. 2006: Routledge.

[16] Löfgren, O., The nation as home or motel? Metaphors of media and belonging. Sosiologisk Årbok, 2001. 14(1): p. 1-34.

[17] Tseng, S.-F. and Y.P. Hsieh, The Implications of Networked Individualism for Social Participation How Mobile Phone, E-mail, and IM Networks Afford Social Participation for Rural Residents in Taiwan. American Behavioral Scientist, 2015: p. 0002764215580620.

[18] Valkenburg, P.M. and J. Peter, Internet communication and its relation to well-being: Identifying some underlying mechanisms. Media Psychology, 2007. 9(1): p. 43-58.

[19] Wang, H., V. Chua, and M.A. Stefanone, Social Ties, Communication Channels, and Personal Well-Being A Study of the Networked Lives of College Students in Singapore. American Behavioral Scientist, 2015: p. 0002764215580590. 